\title{
Caracterização fenotípica e molecular de Zingiber officinale roscoe cultivado no norte de Mato Grosso, Brasil
}

Zingiber officinale Roscoe, popularmente conhecido como gengibre, é cultivado no Brasil por agricultores familiares e por mantenedores de quintais, além de ser utilizado na culinária e como medicamento tradicional. Considerando a importância da espécie, este estudo teve por objetivo caracterizar, utilizando marcadores fenotípicos (quantitativos e qualitativos) e moleculares, genótipos de Zingiber officinale cultivados em quatro municípios do estado de Mato Grosso e, assim, identificar a diversidade genética existente entre os mesmos. Foram caracterizados 30 genótipos a partir de 21 descritores fenotípicos (sete quantitativos e 14 qualitativos) e oito primers SSR. Dentre os descritores quantitativos, a produtividade do rizoma contribuiu em $97 \%$ para a diversidade entre os genótipos, apresentando uma correlação fraca $(r=0,4)$ com a altura da planta e moderada $(r=0,54)$ com o número de perfilhos por planta. Dos 14 descritores para a diversidade entre os genótipos, apresentando uma correlação fraca $(r=0,4)$ com a altura da planta e moderada $(r=0,54)$ com o número de perfilhos por planta. Dos 14 descritores
qualitativos, apenas oito apresentaram polimorfismo, sendo as cores da folha e da polpa do rizoma as características de maior variabilidade. Os primers SSR utilizados foram altamente informativos e apontaram heterozigosidade observada $(\mathrm{Ho})$ menor que a esperada (He). As análises dos dados fenotípicos e moleculares apresentaram diferenças na formação dos grupos genéticos, sendo observada correlação, embora muito fraca $(r \cong 0,05)$, entre os dados quantitativos e moleculares. $A$ análise conjunta apresentou uma correlação moderada $(0,70>r>0,50)$ com as análises fenotípicas (quantitativa e qualitativa) e molecular. A partir da caracterização fenotípica e molecular, isolada e conjunta, foi possível identificar que existe diversidade genética entre os 30 genótipos de Zingiber officinale avaliados, indicando um processo de diferenciação entre as populações e apontando, portanto, a importância da conservação desse material para programas de conservação e melhoramento genético da espécie.

\section{Phenotypic and molecular characterization of Zingiber officinale roscoe cultivated in the north of Mato Grosso, Brazil}

\begin{abstract}
Zingiber officinale Roscoe, popularly known as ginger, is grown in Brazil by family farmers and backyard maintainers, in addition to being used in cooking and as a traditional medicine. Considering the importance of the species, this study aimed to characterize, using phenotypic (quantitative and qualitative) and molecular markers, genotypes of Zingiber officinale cultivated in four municipalities in the state of Mato Grosso, and thus, to identify the genetic diversity existing between them. Thirty genotypes were characterized from 21 phenotypic descriptors (seven quantitative and 14 qualitative) and eight SSR primers. Among the quantitative descriptors, the rhizome productivity contributed $97 \%$ to the diversity between the genotypes, showing a weak correlation $(r=0.4)$ with the height of the plant and moderate $(r=0.54)$ with the number of tillers per plant. Of the 14 qualitative descriptors, only eight showed polymorphism, with a weak correlation $(r=0.4)$ with the height of the plant and moderate $(r=0.54)$ with the number of tillers per plant. Of the 14 qualitative descriptors, only eight showed polymorphism, with
the colors of the rhizome leaf and pulp being the characteristics of greatest variability. The SSR primers used were highly informative and showed observed heterozygosity (Ho) less than expected $(\mathrm{He})$. The analysis of phenotypic and molecular data showed differences in the formation of genetic groups, with a correlation, although very weak ( $r \cong 0.05)$, between quantitative and molecular data. The joint analysis showed a moderate correlation $(0.7>r>0.50)$ with the phenotypic (quantitative and qualitative) and molecular analyses. From the phenotypic and molecular characterization, isolated and joint, it was possible to identify that there is genetic diversity among the 30 genotypes of Zingiber officinale evaluated, indicating a process of differentiation between populations and pointing, therefore, the importance of the conservation of this material for programs of conservation and genetic improvement of the species.
\end{abstract}

Keywords: Genetic resources; Ginger; Joint analysis; Morpho-agronomic descriptors; SSR.

Elisa dos Santos Cardoso (iD

Universidade do Estado de Mato Grosso, Brasil http://lattes.cnpq.br/7863449442902495 http://orcid.org/0000-0001-9477-1743 elisabyo@gmail.com

\section{Ana Aparecida Bandini Rossi (iD)}

Universidade do Estado de Mato Grosso, Brasil http://lattes.cnpq.br/2734433144153549 http://orcid.org/0000-0002-8318-5375

anabanrossi@unemat.br

Uéliton Oliveira Alves

Universidade Estadual do Norte Fluminense Darcy Ribeiro, Brasil

http://lattes.cnpq.br/6230940723952334

http://orcid.org/0000-0002-8617-6044

uelitonalves2011@hotmail.com

Alex Souza Rodrigues
Universidade Estadual do Norte Fluminense Darcy
Ribeiro, Brasil
$\frac{\text { http://lattes.cnpq.br/4426808537274718 }}{\text { http://orcid.org/0000-0003-4040-5654 }}$
$\frac{\text { alexsouzarodrigues@outlook.com }}{\text { Eliane Cristina Moreno de Pedri }}$
Universidade do Estado de Mato Grosso, Brasil
http://lattes.cnpq.br/9596235243976750
http://orcid.org/0000-0002-7044-581X
elicmbio@gmail.com
Auana Vicente Tiago (iD
Universidade do Estado de Mato Grosso, Brasil
http://lattes.cnpq.br/3112795576497501
http://orcid.org/0000-0001-9556-9491
auana bio@hotmail.com

Alex Souza Rodrigues beiro, Brasil

alexsouzarodrigues@outlook.com

Eliane Cristina Moreno de Pedri

Universidade do Estado de Mato Grosso, Brasil

http://lattes.cnpq.br/9596235243976750

elicmbio@gmail.com

Auana Vicente Tiago

http://lattes.cnpq.br/3112795576497501

auana bio@hotmail.com
Kelli Évelin Müller Zortéa (iD

Universidade do Estado de Mato Grosso,

Brasil

http://lattes.cnpq.br/7140876715622617 http://orcid.org/0000-0003-0545-6130 kellimullerz@gmail.com
Referencing this:

CARDOSO, E. S.; ROSSI, A. A. B.; OLIVEIRA, U. A.; RODRIGUES, A. S.; PEDRI, E. C. M.; TIAGO, A. V.; ZORTÉA, K. É. M.. Caracterização fenotípica e molecular de Zingiber officinale roscoe cultivado no norte de Mato Grosso, Brasil. Revista Ibero Americana de Ciências Ambientais, v.12, n.6, p.181-198, 2021. DOI:

http://doi.org/10.6008/CBPC2179-6858.2021.006.0016 


\section{INTRODUÇÃO}

Zingiber officinale Roscoe, popularmente conhecido como gengibre, é uma espécie de origem asiática, atualmente considerada de distribuição pantropical, cujos rizomas são utilizados na culinária e também explorados para fins medicinais, seja por meio de preparos tradicionais ou pela indústria farmacêutica (RAVINDRAN et al., 2016). Os rizomas podem ser comercializados e consumidos in natura, secos ou processados, sendo que na categoria culinária, destaca-se o uso como condimento, aromatizante, preparo de conservas, bebidas e produtos de panificação e confeitaria (CARMO et al., 2015). Na área médica, é utilizado pela medicina tradicional como anti-inflamatório e analgésico, bem como para o tratamento de doenças dos sistemas digestório e respiratório, propriedades também exploradas pela indústria farmacêutica, que ainda desenvolve pesquisas relacionadas ao seu potencial antioxidante, cardioprotetor, neuroprotetor e antitumoral (BALOGUN et al., 2020; CARDOSO et al., 2018; FERREIRA et al., 2020; SRINIVASAN, 2017; WAKCHAURE et al., 2018).

O cultivo de $Z$. officinale é realizado por meio do plantio de fragmentos do rizoma, uma vez que a espécie se reproduz exclusivamente por propagação vegetativa, o que representa uma limitação para sua variabilidade genética e o melhoramento convencional da espécie. Contudo, ao longo de sua história evolutiva, a espécies foi acumulando mutações e adaptações dando origem a diversas variedades, geralmente nomeadas em homenagem ao local de cultivo, como, por exemplo, as variedades jamaicanas, havaiana, gigante japonesa e a gigante chinesa. Os programas de melhoramento da espécie, em sua maioria, realizam a avaliação e seleção de genótipos nativos e de variações clonais que ocorrem naturalmente, embora a mutação induzida também venha sendo explorada (BLANCO et al., 2016; RAVINDRAN et al., 2016, SHIVAKUMAR, 2020).

A espécie Z. officinale é cultivada principalmente no continente asiático, sendo a Índia e a China os maiores produtores mundiais, com produção de, aproximadamente, $1.000 .000 \mathrm{Mg}$ (megagramas) e 500.000 Mg, respectivamente (NATIONMASTER, 2020a). No Brasil, a produção anual estimada para 2017 foi de 23.626 Mg, um aumento de aproximadamente $112 \%$ em relação ao censo agropecuário de 2006 , sendo o estado do Espírito Santo o maior produtor com $17.708 \mathrm{Mg}$, o equivalente a, aproximadamente, $75 \%$ da produção nacional (SIDRA, 2017). Considerando as exportações, o Brasil apresentou um aumento de 164\% entre 2006 e 2019, quando o país foi classificado como o oitavo maior exportador no ranking mundial (NATIONMASTER, 2020b).

A produção comercial de Z. officinale, no Brasil é realizada principalmente por agricultores familiares (SIDRA, 2017), sendo o cultivo para consumo próprio e/ou comércio local bastante disseminado e caracterizado como uma forma de conservação on farm, pois contribui para conservação da diversidade genética da espécie por meio das técnicas de manejo e uso (SANTONIERI et al., 2016). Apesar da importância comercial da espécie, poucas são as pesquisas relacionadas à sua caracterização morfoagronômica e genética, especialmente, em relação às variedades oriundas de conservação on farm ou de produção local. Os estudos de caracterização, os bancos de germoplasma e, consequentemente, os programas de 
melhoramento genético da espécie estão concentrados na Ásia, região de maior produção mundial, sendo escassos os trabalhos que avaliam o germoplasma brasileiro (AKSHITHA et al., 2019; BABU et al., 2017; BASAK et al., 2019; BLANCO et al., 2015; BLANCO et al., 2017; DAS et al., 2020).

A caracterização do germoplasma de Z. officinale, particularmente os de cultivo local e/ou conservação on farm, é de grande importância para programas de melhoramento genético, uma vez que permite a identificação de genótipos com características desejáveis para o cultivo comercial da espécie, como adaptabilidade a diferentes condições edafoclimáticas, produtividade e resistência a pragas e doenças (SHIVAKUMAR, 2020).

Nesse contexto, este estudo objetivou caracterizar, por meio de marcadores fenotípicos (quantitativos e qualitativos) e moleculares, genótipos de Zingiber officinale cultivados em Mato Grosso e, assim, identificar a diversidade genética existente entre os mesmos.

\section{MATERIAIS E MÉTODOS}

Foram avaliados 30 genótipos de Zingiber officinale, coletados em quintais urbanos e rurais de quatro municípios mato-grossenses, sendo onze provenientes de Alta Floresta (AF), seis de Apiacás (AP), cinco de Nova Mutum (NM) e oito de Peixoto de Azevedo (PXT) (Figura 1).

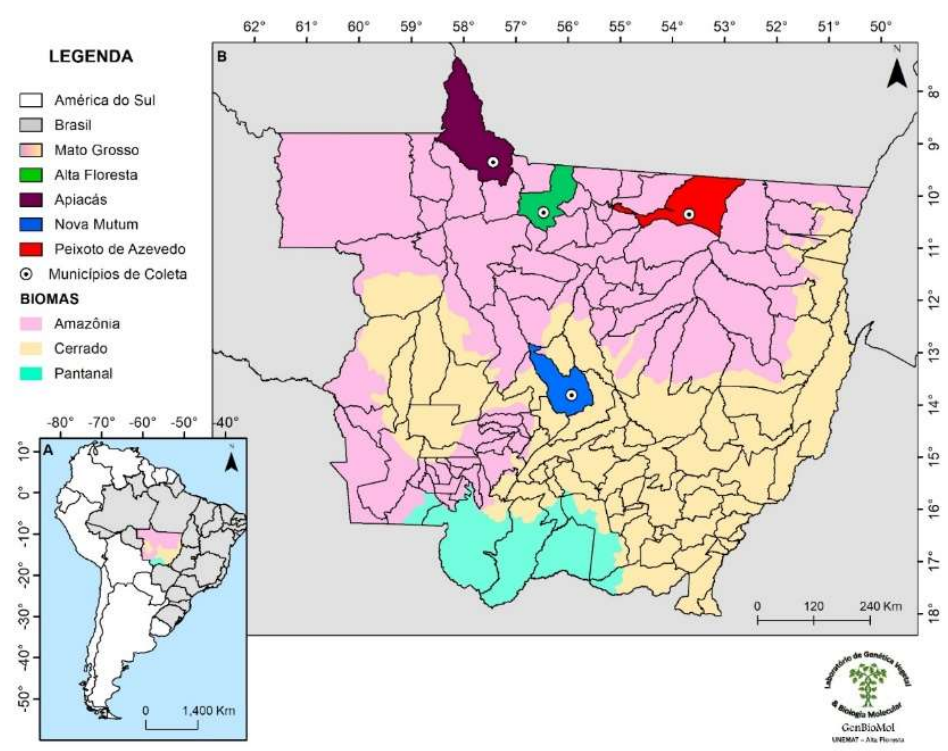

Figura 1: Localização geográfica dos municípios mato-grossenses onde foram coletados os genótipos de Zingiber officinale. A: Localização do estado de Mato Grosso na América do Sul; B: municípios mato-grossenses onde foram realizadas as coletas.

Alta Floresta, Apiacás e Peixoto de Azevedo estão localizados na mesorregião norte mato-grossense e fazem parte do bioma amazônico, que ocupa cerca de 54\% do território do estado de Mato Grosso (SILVA et al., 2015), e apresentam clima do tipo Am (tropical úmido ou subúmido). Nova Mutum, por sua vez, apesar de situado na mesma mesorregião, está localizado no bioma cerrado, com clima do tipo Aw (tropical com inverno seco) (ALVARES et al., 2013).

O material vegetal coletado consistiu em rizomas (para plantio e avaliação fenotípica) e folhas jovens (para avaliação molecular) de indivíduos de Z. officinale cultivados, para consumo próprio, em quintais 
urbanos e rurais. Os mantenedores dos quintais mantêm esses genótipos ao longo do tempo, colhendo e replantando a cada ano, de modo que já não sabem informar a origem dos mesmos, caracterizando o material de estudo como proveniente de sistema de conservação on farm.

\section{Caracterização fenotípica}

Indivíduos de Z. officinale foram cultivados e avaliados em Casa de Vegetação da Universidade do Estado de Mato Grosso Carlos Alberto Reyes Maldonado (UNEMAT), campus de Alta Floresta, Mato Grosso, Brasil. O plantio foi realizado em vasos plásticos de 12 litros de capacidade $(50 \times 17 \times 14 \mathrm{~cm})$, sendo que cada genótipo foi plantado em quadruplicata, à $5 \mathrm{~cm}$ de profundidade, e utilizando, aproximadamente, $5 \mathrm{~cm}$ de rizoma. O solo utilizado foi coletado em propriedade rural do município de Alta Floresta e analisado pelo Laboratório de Análise do Solos, Adubos e Foliar (LASAF) da UNEMAT/Alta Floresta, sendo realizada adubação 30 dias após o plantio, conforme orientação técnica. A manutenção do experimento foi realizada por meio de capina manual e, para proteção dos rizomas expostos, utilizou-se a técnica de amontoa (CARMO et al., 2015).

O plantio foi irrigado diariamente por microaspersão automática durante 15 minutos, e mantido em temperatura média de $29^{\circ} \mathrm{C}$. Após a emergência, o pseudocaule principal de cada indivíduo foi demarcado com fita vermelha para posterior quantificação dos perfilhos e avaliação dos demais descritores fenotípicos.

Para caracterização dos genótipos foram utilizados sete descritores fenotípicos quantitativos (Tabela 1) e 14 qualitativos (Tabela 2), perfazendo um total de 21 descritores propostos por Wicaksana et al. (2011) e Blanco et al. (2017). Os descritores fenotípicos foram avaliados no período máximo de crescimento vegetativo ou pós colheita, correspondendo há cinco e sete meses pós plantio, respectivamente.

Tabela 1: Descritores fenotípicos quantitativos avaliados em genótipos de Zingiber officinale.

\begin{tabular}{ll}
\hline Característica & Método de avaliação \\
\hline Altura da planta (AP) & $\begin{array}{l}\text { Mensuração da superfície do solo até a extremidade final da última folha do primeiro } \\
\text { perfilho }(\mathrm{cm})^{*}\end{array}$ \\
\hline Comprimento da folha (CF) & Mensuração do pecíolo até o ápice da folha $(\mathrm{cm})^{*}$ \\
\hline Largura da folha (LF) & Mensuração na região mediana da folha $(\mathrm{cm})^{*}$ \\
\hline Número de perfilhos por planta (NPP) & Contagem do número de perfilhos ${ }^{* *}$ \\
\hline Número de folhas por perfilho (NFP) & Contagem do número de folhas por perfilho* \\
\hline Espessura do rizoma (ER) & Mensuração dos rizomas $(\mathrm{mm})^{*}$ \\
\hline $\begin{array}{l}\text { Produtividade dos rizomas por indivíduo } \\
\text { (PRI) }\end{array}$ & Pesagem dos rizomas $(\mathrm{g})^{* *}$
\end{tabular}

Avaliações realizadas em: máximo de crescimento vegetativo $\left({ }^{*}\right)$ e pós-colheita $\left({ }^{* *}\right)$.

Tabela 2: Descritores fenotípicos qualitativos avaliados em genótipos de Zingiber officinale.

\begin{tabular}{|c|c|}
\hline Característica & Classes Fenotípicas \\
\hline Hábito de crescimento $(\mathrm{HC})^{*}$ & 1- Ereto; 2- Semiereto; 3- Semiacamado; 4- Acamado. \\
\hline Forma da lígula $(\mathrm{FL})^{*}$ & $\begin{array}{l}\text { 1- Membranosa glabra; 2- Membranosa ciliada ou pilosa; } \\
\text { 3- Linhas de cílios. }\end{array}$ \\
\hline $\begin{array}{l}\text { Padrão de união da bainha } \\
\text { (PUB) }\end{array}$ & 1- Compactada; 2- Livre (Frouxa); 3 - Outra \\
\hline Tamanho da lígula $(\mathrm{TL})^{*}$ & $\begin{array}{l}\text { 0- Ausente; 1-Curta (<3mm); 2- Média (3 a } 6 \text { mm); } \\
\text { 3- Comprida (> } 6 \mathrm{~mm}) \text {. }\end{array}$ \\
\hline Margem da lígula (ML) ${ }^{*}$ & 1- Inteira; 2- Serrilhada; 3- Dentada. \\
\hline Pubescência da folha (PF)* & $\begin{array}{l}\text { 1- Glabra; 2- Face superior pubescente; 3- Face inferior pubescente; 4- Ambas as faces } \\
\text { pubescentes; 5-Outro. }\end{array}$ \\
\hline Divisão da folha (DF) ${ }^{*}$ & 1- Simples; 2- Composta. \\
\hline
\end{tabular}




\begin{tabular}{|c|c|}
\hline Forma da folha (FF) ${ }^{*}$ & 1- Lanceolada; 2- Linear; 3- Elíptica; 4- Oblonga. \\
\hline Ápice da folha (AF) ${ }^{*}$ & 1- Aristado; 2- Acuminado; 3- Caudado; 4- Moderadamente agudo; 5- Fortemente agudo. \\
\hline Orientação da folha (OF)* & 1- Alternada; 2- Oposta; 3- Basal. \\
\hline $\begin{array}{l}\text { Padrão de união da folha } \\
\text { (PUF) }\end{array}$ & 1- Séssil; 2- Semiséssil; 3- Peciolada; 4- Invaginante; 5- Outros. \\
\hline Cor da folha (CF) ${ }^{*}$ & 1- Verde; 2- Verde amarelada; 3- Verde escura. \\
\hline Cor da pele do rizoma (CPR) ${ }^{* *}$ & $\begin{array}{l}\text { 1- Amarela clara; 2- Amarela; 3- Marrom clara; } \\
\text { 4- Avermelhada; }\end{array}$ \\
\hline $\begin{array}{l}\text { Cor da polpa do rizoma } \\
(\mathrm{CPoR})^{* *}\end{array}$ & 1- Amarela clara; 2- Amarela; 3- Amarela escura. \\
\hline
\end{tabular}

Avaliações realizadas em: máximo de crescimento vegetativo $\left({ }^{*}\right)$ e pós-colheita $\left({ }^{* *}\right)$.

\section{Caracterização molecular}

Para as análises moleculares, folhas jovens foram coletadas, envoltas em papel toalha e acondicionadas em saco plástico, com fecho hermético, devidamente identificado e contendo sílica gel. Após a desidratação, as folhas foram transferidas para envelopes de papel alumínio e armazenadas sob refrigeração $\left(-20^{\circ} \mathrm{C}\right)$. A extração do DNA total e as amplificações foram realizadas no Laboratório de Genética Vegetal e Biologia Molecular (GenBioMol), Centro de Pesquisa e Tecnologia da Amazônia Meridional (CEPTAM), da UNEMAT, campus de Alta Floresta, Mato Grosso, Brasil.

Para extração do DNA total, aproximadamente, $400 \mathrm{mg}$ de material vegetal foliar foram triturados, na presença de nitrogênio líquido, e utilizou-se o protocolo CTAB (Cationic Hexadecyltrimethyl Ammonium Bromide), descrito por Doyle et al. (1987), com algumas modificações: acréscimo de $2 \%$ de PVP (polivinilpirrolidona) e aumento de 2 para $5 \%$ e de 0,2 para $2 \%$ nas concentrações de CTAB e $\beta$ mercaptoetanol, respectivamente, no tampão de extração. A qualidade e a integridade do DNA foram verificadas por meio de eletroforese em gel de agarose $1 \%$ corado com brometo de etídio $\left(10 \mathrm{mg} \mathrm{mL}^{-1}\right)$, enquanto a quantidade foi estimada, por meio de avaliação visual, por comparação com DNA $\lambda\left(100 \mathrm{ng}^{-1} \mathrm{~L}^{-1}\right.$ ).

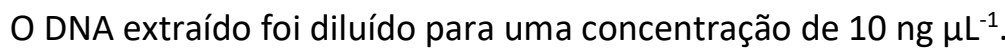

Para análise da diversidade genética foram utilizados oito primers SSR (Simple Sequence Repeat) descritos por Lee et al. (2007). As amplificações via PCR (Polymerase Chain Reaction) foram realizadas em um volume de $10 \mu \mathrm{L}$, contendo $3 \mu \mathrm{L}$ de $5 X$ Colorless GoTaq ${ }^{\circledR}$ Reaction Buffer, 0,6 $\mu \mathrm{L}$ de $\mathrm{MgCl}_{2}(25 \mathrm{mM}), 0,8$ $\mu \mathrm{L}$ de $\mathrm{dNTP}(2,5 \mathrm{mM}), 0,25 \mu \mathrm{L}$ de cada primer $(20 \mu \mathrm{M}), 0,12 \mu \mathrm{L}$ de taq DNApolimerase (5U), $2 \mu \mathrm{L}$ de DNA (10 ng) e água Milli-Q ${ }^{\circledR}$ para completar o volume total. As amplificações foram conduzidas em termociclador Aeris ${ }^{\circledR}$, sendo que o programa consistiu em desnaturação inicial por 5 minutos à $94{ }^{\circ} \mathrm{C}$, seguidos de 30 ciclos de $94{ }^{\circ} \mathrm{C}$ por 30 segundos, 45 segundos na temperatura de anelamento (TA) específica para cada primer e 72 ${ }^{\circ} \mathrm{C}$ por 45 segundos, e de 8 ciclos de $94{ }^{\circ} \mathrm{C}$ por 30 segundos, 45 segundos na temperatura de anelamento (TA) específica para cada primer $+5{ }^{\circ} \mathrm{C}$ e $72{ }^{\circ} \mathrm{C}$ por 45 segundos, sendo a extensão final à $72{ }^{\circ} \mathrm{C}$ por 10 minutos. Os produtos de amplificação foram separados em gel de agarose $1,5 \%$, corado em solução de brometo de etídio $\left(0,6 \mu \mathrm{gL}^{-1}\right)$. Os géis de quantificação e dos produtos de amplificação foram visualizados em transiluminador UVB (Loccus Biotecnologia ${ }^{\circledR}$ - LTB-STi), enquanto o registro das imagens foi realizado com fotodocumentador e software L-Pix Sti (Loccus Biotecnologia ${ }^{\circledR}$ ). 


\section{Análises Estatísticas}

\section{Caracterização fenotípica}

Os dados fenotípicos foram avaliados com auxílio do programa Genes ${ }^{\circledR}$ (CRUZ, 2016). Para avaliação dos dados fenotípicos quantitativos, as médias obtidas para cada descritor foram utilizadas para determinar a importância dos descritores, conforme proposto por Singh (1981), para avaliar coeficiente de correlação de Pearson e para predição da distância genética por meio do método UPGMA (Unweighted Pair-Group Method Using Arithmetic Average), sendo para isso convertidas em uma matriz de distância euclidiana. Os dados fenotípicos qualitativos, por sua vez, foram avaliados como multicategóricos binários qualitativos, onde se atribui "0" quando uma classe estava ausente no descritor e "1" quanto a mesma estava presente. Essa metodologia é fundamentada em Cole-Rodgers et al. (1997) e pode ser aplicada aos casos em que os genótipos avaliados apresentem mais de uma classe para cada descritor (CRUZ, 2006), como observado para Z. officinale. Para obtenção da matriz de dissimilaridade, empregada na construção do dendrograma pelo método UPGMA, foi utilizado o índice de dissimilaridade correspondente à distância euclidiana média (Equação 1).

$$
d_{i i^{\prime}}=\sqrt{\frac{1}{v} \sum_{j=1}^{v} \frac{b_{j}+c_{j}}{n_{j}}}
$$

Onde $n j=a j+b j+c j+d j$, ou seja, número de categorias apresentadas pela j-ésima variável; $a$ = número de concordância do tipo 1-1, b = número de discordância do tipo 1-0, c = número de discordância do tipo 0-1; d = número de concordância do tipo 0-0 para a j-ésima variável e v = número de variáveis. Ainda para os dados qualitativos, foi estimado o percentual de polimorfismo dos descritores avaliados, bem como a frequência de suas classes.

\section{Diversidade genética}

Para análise dos dados moleculares, os produtos de amplificação foram analisados com auxílio do software Lablmage 1D (Loccus Biotecnologia ${ }^{\circledR}$ ), onde o tamanho dos fragmentos amplificados foi estimado, por comparação, com o marcador molecular Cellco de 100 pb DNA Ladder. A frequência alélica, a diversidade gênica, o conteúdo de informação polimórfica (PIC), a heterozigosidade esperada e observada foram determinadas com auxílio do programa Power Marker V.3.25 (LIU et al., 2005), sendo a matriz de distância genética de Nei (1973) importada para o programa Genes ${ }^{\circledast}(C R U Z, 2016)$ para construção do dendrograma pelo método UPGMA, sendo o ponto de corte estimado pelo coeficiente de Mojena (MOJENA, 1977), com k $=1,25$, e a validação dos grupos determinada, de acordo com Sokal et al. (1962), pelo coeficiente de correlação cofenética (CCC).

\section{Estrutura populacional}

O número de grupos genéticos (K) foi obtido pelo programa "Structure ${ }^{\circledR ” ~(P R I T C H A R D ~ e t ~ a l ., ~ 2000), ~}$ baseado em estatística bayesiana, sendo realizadas 20 corridas para cada valor de K, 250.000 "burn-ins" e 750.000 simulações de Monte Carlo de Cadeias de Markov (MCMC). Para definição do K mais provável, foram utilizados os critérios propostos por Evano et al. (2005) e Pritchard et al. (2009).

O suplemento GenAIEx ${ }^{\circledast} 6.5$ (PEAKALL et al., 2012) foi empregado para realização da Análise das 
Coordenadas Principais (PCOA) e para estimativa do número de alelos raros e exclusivos. As três principais coordenadas foram plotadas em gráfico tridimensional com auxílio do programa SigmaPlot ${ }^{\circledR}$ v.12.0 (SYSTAT SOFTWARE, 2011). A avaliação da distribuição da diversidade genética entre e dentro das populações por meio da Análise de Variância Molecular (AMOVA), foi realizada com auxílio do programa Arlequin ${ }^{\circledast} 3.0$ (EXCOFFIER et al., 2005), enquanto software PopGene ${ }^{\circledR} 1.32$ (YEH et al., 2000) foi utilizado para estimativa do fluxo gênico $(\mathrm{Nm})$.

\section{Análise Conjunta}

Com auxílio do programa Genes ${ }^{\circledR}$ (CRUZ, 2016), foi obtida uma matriz conjunta de distância para análise da distância dos genótipos considerando simultaneamente as variáveis fenotípicas (qualitativas e quantitativas) e moleculares, utilizado o algoritmo proposto por Gower (1971), conforme equação 2:

$$
\mathrm{S}_{\mathrm{ijk}}=\frac{\sum_{\mathrm{k}=1}^{\mathrm{p}} \mathrm{W}_{\mathrm{ijk}} \cdot \mathrm{S}_{\mathrm{ijk}}}{\sum_{\mathrm{k}=1}^{\mathrm{p}} \mathrm{W}_{\mathrm{ijk}}}
$$

Onde k é o número de variáveis e p é número total de características avaliadas; i e j: dois genótipos quaisquer; Wijk: peso dado a comparação ijk, atribuindo valor 1 para comparações válidas e valor 0 para quando o valor da variável está ausente em um ou ambos genótipos; Sijk: contribuição da variável k na similaridade entre os genótipos i e j, com valores entre 0 e 1. Para uma variável nominal, se o valor de $k$ é a mesmo para os genótipos i e j, então Sijk = 1, caso contrário, Sijk = 0; para uma variável contínua Sijk $=1-|X i k-X j k| / R k$, onde Xik e Xjk correspondem aos valores da variável $k$ para i e j, respectivamente, e Rk é a amplitude de variação da variável $k$ na amostra. A divisão por Rk elimina as diferenças entre escalas das variáveis, produzindo um valor dentro do intervalo $[0,1]$ e pesos iguais.

As matrizes de dissimilaridade foram utilizadas para avaliação da diversidade genética por meio do agrupamento dos genótipos pelo método hierárquico UPGMA, considerando os dados moleculares e os fenotípicos qualitativos e quantitativos simultaneamente. Para a estimativa da significância da correlação (associação) entre as matrizes de dissimilaridade obtidas para os dados fenotípicos e moleculares, foi empregado o teste de comparação de matrizes de Mantel (teste-Z), com 1000 permutações (MANTEL, 1967).

\section{RESULTADOS E DISCUSSÃO}

Considerando os sete descritores quantitativos e utilizando o método hierárquico UPGMA para avaliação da diversidade genética, os 30 genótipos de $Z$. officinale foram distribuídos em quatro grupos (Figura 2), sendo a maior distância genética encontrada entre os genótipos AF11 e PXT06 $(1,76)$ e menor distância $(0,18)$, entre AP01 e PXT03.

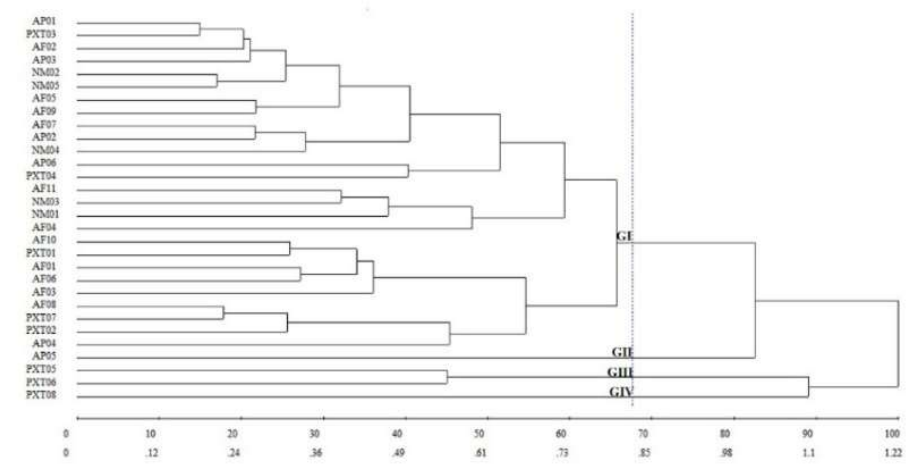

Figura 2: Dendrograma obtido pelo método UPGMA, baseado em distância euclidiana, considerando sete descritores fenotípicos quantitativos para Zingiber officinale. Alta Floresta (AF), Apiacás (AP), Nova Mutum (NM) e Peixoto de Azevedo (PXT); Ponto de Corte: 0,83 (68\%); Coeficiente de Correlação Cofenética (CCC): 0,80. 
O grupo I é o mais representativo (87\%), compreendendo genótipos dos quatro municípios de abrangência do estudo e apresentando grande variabilidade para os descritores avaliados. O grupo II, composto apenas pelo genótipo AP05, se destacou dos demais por apresentar o maior número de folhas por perfilho, enquanto o grupo III é composto por genótipos coletados em Peixoto de Azevedo que se diferenciaram por apresentarem os menores valores para comprimento e largura da folha, espessura e produtividade do rizoma. O grupo IV, por sua vez, é constituído pelo genótipo PXT08, cuja produtividade e número de perfilhos por folha foram determinantes para separá-lo do grupo anterior (Figura 3).
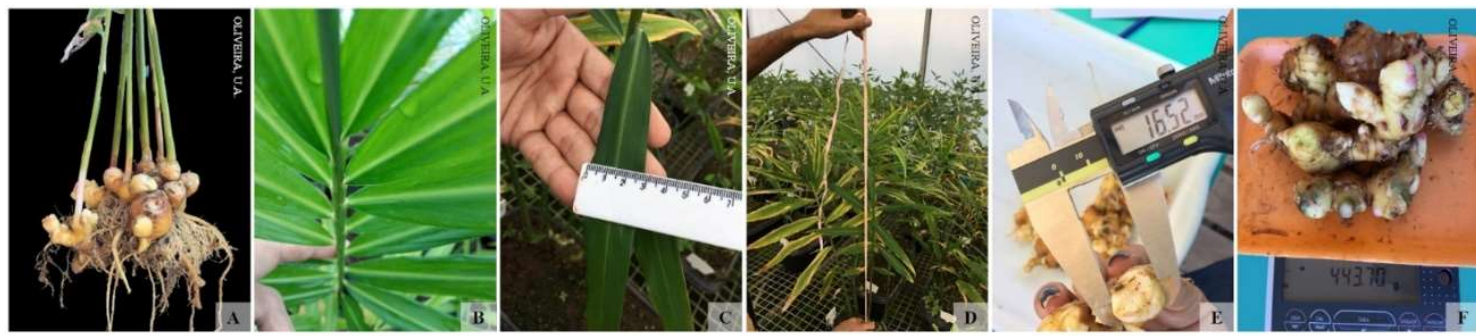

Figura 3: Descritores fenotípicos quantitativos que mais contribuíram para o agrupamento dos acessos de Zingiber officinale pelo método UPGMA. A: número de perfilhos por planta; B: número de folhas por perfilho; C: largura da folha; D: altura da planta; E: espessura do rizoma; F: produtividade do rizoma.

Dentre os sete descritores quantitativos avaliados, a produtividade do rizoma por indivíduo (PRI) variou entre 86,83 g e 419,34 g e contribuiu em $97 \%$ para a diversidade genética entre os genótipos, sendo esta uma categoria de grande valor agronômico e uma das principais a ser considerada na escolha de material para propagação e cultivo comercial de Z. officinale. A PRI apresentou correlação positiva e significativa com a AP, LF, CF, ER ( $p \leq 0,05)$ e NPP ( $p \leq 0,01)$. Os coeficientes de correlação variaram entre 0,40 (PRI x AP) e 0,54 (PRI x NPP) e, considerando que para correlação de Pearson o quadrado de seu coeficiente represente uma estimativa (\%) de quanto a variação de um descritor é explicada pela variação de outro (MIOT, 2018), é possível verificar que mesmo entre os descritores com maior correlação (PRI e NPP), essa influência é de apenas $29 \%$, permitindo inferir que, apesar de significativa, é uma correlação fraca.

Nandkangre et al. (2016), ao estudar a variabilidade genética entre 56 acessos de $Z$. officinale oriundos de Burkina Faso, observaram, diferentemente deste estudo, que a PRI apresentou menor correlação com NPP e maior correlação com a AP. A influência da altura da planta na produtividade do rizoma também foi constatada por Blanco et al. (2017), ao avaliar a diversidade genética de 61 acessos de Z. officinale oriundos do banco de germoplasma do Departamento de Genética da ESALQ/USP, onde valores de correlação entre produtividade, AP e NPP foram maiores que os observados nesse estudo. Essas divergências podem ser atribuídas tanto às metodologias adotadas para implantação do experimento (cultivo em campo e em casa de vegetação), quanto à origem do material, considerando que neste estudo foram avaliados genótipos oriundos de conservação on-farm.

Os genótipos avaliados nesse estudo foram classificados, de acordo com as diretrizes para avaliação da distinção, uniformidade e estabilidade (DUS) de Z. officinale (PPV \& FRA, 2007), como genótipos baixos, com poucos perfilhos por planta, poucas folhas por perfilho, sendo estas curtas e estreitas, e com rizomas estreitos, com exceção do AP04, cujos rizomas apresentaram espessura média. Esses resultados 
assemelham-se aos obtidos por Basak et al. (2019) e Akshitha et al. (2019) na caracterização de genótipos oriundos de diferentes regiões da Índia.

Características fenotípicas quantitativas representam alto valor adaptativo, são, geralmente, multialélicas e resultam da interação entre muitos genes (HARTL et al., 2010), além de serem fortemente influenciadas por condições ambientais (VIEIRA et al., 2008), como variações na temperatura, umidade, pH e nutrientes disponíveis no solo, de modo que a realização do experimento em casa de vegetação, com os genótipos expostos às mesmas condições, permite inferir que as diferenças observadas neste estudo tão relacionadas à sua base genética.

A avaliação dos 14 descritores fenotípicos qualitativos demonstrou que os 30 genótipos de $Z$. officinale não apresentaram variação quanto a forma e margem da lígula (FL e ML), pubescência, divisão, orientação e padrão de união da folha (PF, DF, OF e PUF), sendo que todos os indivíduos apresentaram lígula membranosa glabra, com margem inteira e folhas sem pelos, com divisão simples, orientação alternada e padrão de união semiséssil. Com exceção da forma da lígula (FL), a homogeneidade dos demais descritores (ML, PF, DF, OF e PUF) também foi observada por Blanco (2015), ao avaliar acessos de Z. officinale oriundos da Colômbia e de diferentes estados do Brasil e mantidos no Banco de Germoplasma da ESALQ/USP, sendo que está similaridade demonstrou a baixa variabilidade genética da espécie, o que pode ser atribuído à reprodução por propagação vegetativa.

Por não terem contribuído para diferenciação entre os genótipos, os descritores $F L, M L, P F, D F, O F$ e PUF não foram utilizados para as demais análises de diversidade genética. Os oito descritores que contribuíram para avaliação da diversidade genética apresentaram $67 \%$ de polimorfismo, indicando a sua eficiência na diferenciação entre os genótipos, sendo a frequência de suas classes fenotípicas apresentada na figura 4.

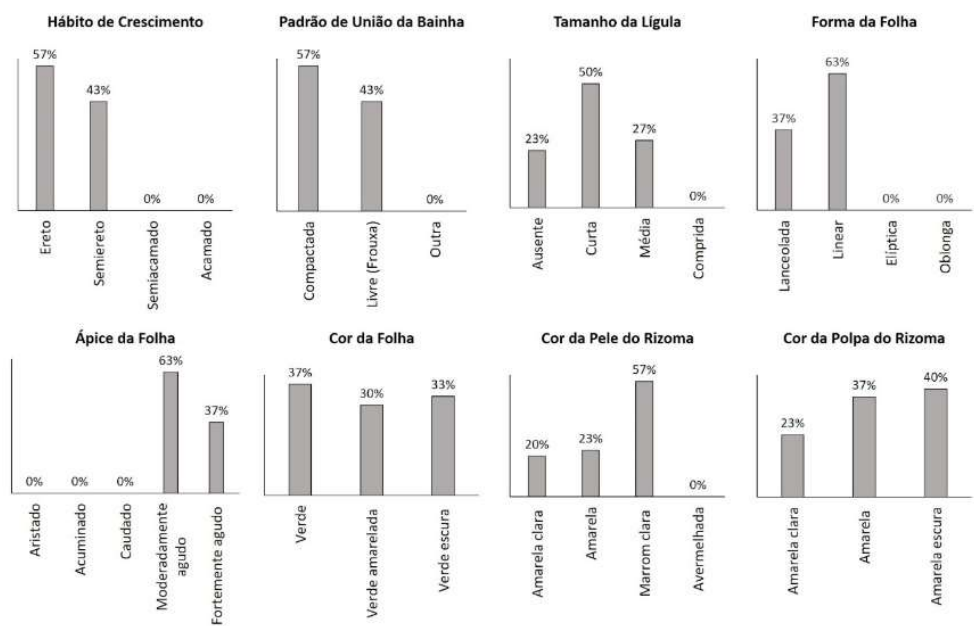

Figura 4: Distribuição da frequência das classes fenotípicas dos descritores qualitativos polimórficos utilizados para estudo do polimorfismo de Zingiber officinale. Avaliação realizada no máximo de crescimento vegetativo.

Os descritores cor da folha (CF) e cor da polpa do rizoma (CPOR) foram os que mais apresentaram variação, considerando que os indivíduos avaliados se distribuíram entre todas as classes possíveis para estas características. Já a forma e o ápice da folha (FF e AF) foram os que menos divergiram entre os acessos, sendo que $63 \%$ apresentaram folha linear com ápice moderadamente agudo. 
A análise dos dados, utilizando o método UPGMA, resultou em cinco grupos genéticos distintos (Figura 5), sendo que no grupo I, o mais representativo (30\%), estão os genótipos de menor distância genética $(0,25)$ entre si: PXT01 - AF10, PXT01 - AF07 e NM04 - AF09. Medidas de dissimilaridade genética são importantes por evidenciarem a variabilidade genética do material estudado, conforme demonstrado neste estudo onde a distância média foi de 0,56 e a máxima de 0,74 (NM04 - AP06 e PXT05 - AP03).

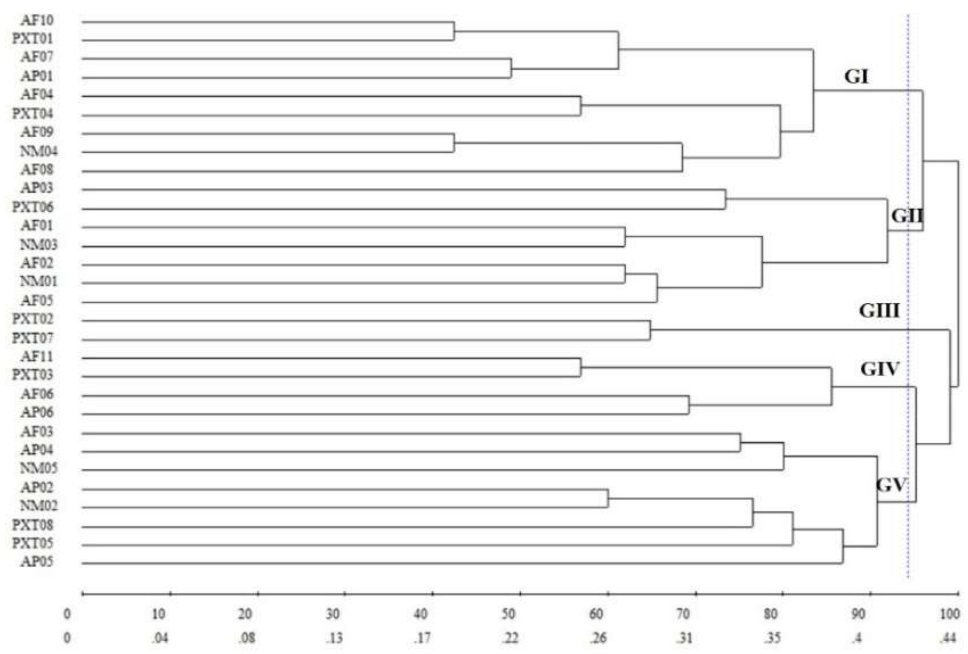

Figura 5: Dendrograma obtido pelo método UPGMA, considerando oito descritores fenotípicos qualitativos para Zingiber officinale. Alta Floresta (AF), Apiacás (AP), Nova Mutum (NM) e Peixoto de Azevedo (PXT); Ponto de Corte: 0,55 (93\%); Coeficiente de Correlação Cofenética (CCC): 0,63.

Diferentemente dos caracteres quantitativos, os qualitativos são de herança monogênica ou oligogênica, sendo pouco influenciado pelo ambiente (BERNARDO, 2010), o que é demonstrado nos grupos I, II, IV e V, compostos por acessos oriundos de cultivo local, on farm, em biomas distintos, indicando que a variabilidade encontrada entre os grupos e ainda a formação de subgrupos pode ser atribuída ao acúmulo de mutações em sua história evolutiva, processo comum em espécies de reprodução assexuada (JATOI et al., 2015).

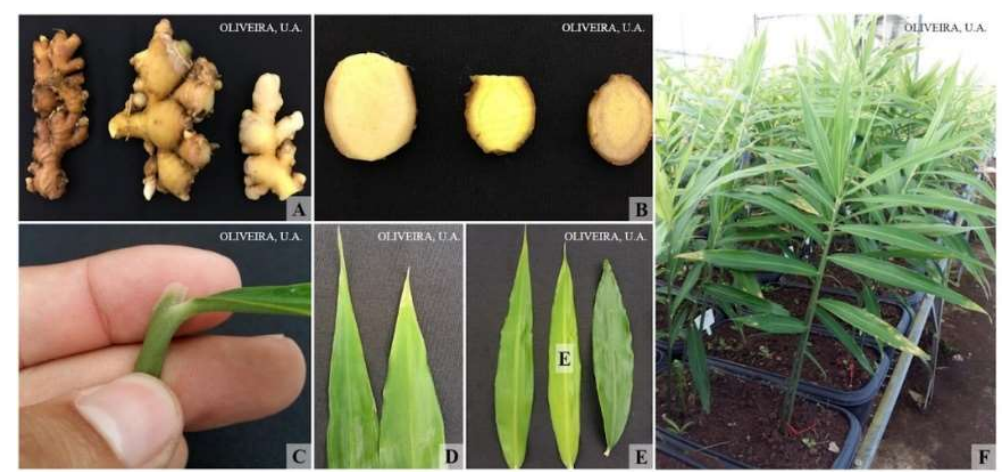

Figura 6: Descritores fenotípicos qualitativos que mais contribuíram para o agrupamento dos genótipos de Zingiber officinale pelo método UPGMA. A: cor da pele do rizoma; B: cor da polpa do rizoma; C: tamanho da lígula e padrão de união da bainha; D: ápice da folha; E: cor da folha; hábito de crescimento.

As classes fenotípicas que mais contribuíram para diferenciação dos grupos foram a coloração marrom clara da pele do rizoma e sua polpa amarela escura (Grupo I), união da bainha ao caule de forma compactada (Grupo II), lígula curta, ápice da folha moderadamente agudo, folha verde amarelada, pele e polpa do rizoma com coloração amarela clara (Grupo III), hábito de crescimento semiereto e bainha unida ao caule de forma livre (Grupo IV) (Figura 6). O grupo V, por sua vez, é composto por indivíduos que não 
apresentaram distribuição uniforme para nenhuma das classes fenotípicas.

A diversidade encontrada neste estudo foi observada, preliminarmente, por meio do hábito de crescimento e coloração da folha e, logo após a colheita, pela coloração da pele do rizoma, uma característica de importância comercial, considerando que a aparência é um dos fatores considerados pelo consumidor para escolha do produto.

\section{Caracterização Molecular}

Os oito primers SSR utilizados, revelaram heterozigosidade observada $(\mathrm{Ho})$ média inferior à esperada (He), sugerindo excesso de homozigotos (Tabela 3).

Tabela 3: Estimativas de parâmetros de diversidade para os oito primers SSR, considerando quatro populações de Zingiber officinale: Alta Floresta, Apiacás, Nova Mutum e Peixoto de Azevedo. Heterozigosidade esperada (He), heterozigosidade observada $(H o)$, índice de fixação de alelos $(f)$ e conteúdo de informação polimórfica (PIC).

\begin{tabular}{|c|c|c|c|c|}
\hline Primers & $\mathrm{He}$ & Ho & $f$ & PIC \\
\hline GB - ZOM - 033 & 0,758 & 0,000 & 1,000 & 0,715 \\
\hline GB - ZOM - 040 & 0,759 & 0,034 & 0,956 & 0,717 \\
\hline GB - ZOM - 055 & 0,788 & 0,000 & 1,000 & 0,754 \\
\hline GB - ZOM - 064 & 0,870 & 0,793 & 0,106 & 0,858 \\
\hline GB - ZOM - 103 & 0,781 & 0,929 & $-0,172$ & 0,745 \\
\hline GB - ZOM - 107 & 0,464 & 0,000 & 1,000 & 0,357 \\
\hline GB - ZOM - 111 & 0,865 & 1,000 & $-0,138$ & 0,849 \\
\hline GB - ZOM - 140 & 0,848 & 1,000 & $-0,162$ & 0,829 \\
\hline Média & 0,767 & 0,470 & 0,403 & 0,728 \\
\hline
\end{tabular}

Os resultados de $\mathrm{He}$ demonstram que, a partir dos primers utilizados, esperava-se uma alta diversidade no material analisado, contudo a média de $\mathrm{Ho}$ foi inferior à de $\mathrm{He}$, gerando um índice de fixação médio de 0,403 e indicando que o material avaliado apresenta baixo número de heterozigotos. Todavia, os resultados apontam para diversidade genética moderada, considerando que os primers GB - ZOM - 103, GB - ZOM - 111 e GB - ZOM - 140 tenham apresentaram $\mathrm{Ho}>\mathrm{He}$, o que corresponde à alta variabilidade, elevado número de heterozigotos e, consequentemente, ausência ou reduzida fixação de alelos.

Lee et al. (2007), ao desenvolver os primers utilizados neste estudo, realizaram a caracterização de 20 acessos de $Z$. officinale, obtendo número de alelos inferior ao deste estudo (34), contudo também observou uma média de $\mathrm{Ho}<\mathrm{He}$. Estudos utilizando marcadores microssatélites têm apontado a presença de polimorfismo para espécie, embora, a análise dos dados seja frequentemente realizada a partir de uma matriz de presença e ausência dos fragmentos amplificados (DAS et al., 2017; DAS et al., 2020; PANDOTRA et al., 2013; SUBUDHI et al., 2016).

O conteúdo de informação polimórfica (PIC) estima a eficiência do primer em detectar a variabilidade genética considerando tanto o número de alelos encontrados quanto a frequência dos mesmos (CRUZ et al., 2011). O conjunto de primers SSR utilizados neste estudo é classificado como altamente informativo, com $88 \%$ dos primers apresentando PIC $>0,5$ e um valor médio próximo a um $(1,0)$, o que, segundo Botstein et al. (1980), são características desejáveis para estudos de caracterização molecular e diversidade genética.

A avaliação da diversidade genética a nível de genótipo, por meio da distância genética de Nei (1973), aponta para maior dissimilaridade entre o genótipo PXT06 e os genótipos AP02 e NM05 (0,8571), enquanto 
a maior similaridade foi encontrada entre os genótipos AF02 e AF03 (0,0714). A dissimilaridade média entre os genótipos foi de 0,5572, permitindo inferir que existe uma considerável diversidade genética entre os genótipos de Z. officinale avaliados, o que pode ser visualizado por meio do método de agrupamento UPGMA (Figura 7A), que dividiu os genótipos em cinco grupos, enquanto o agrupamento realizado por meio da análise bayesiana, resultou em três grupos genéticos (Figura 7B). A análise das coordenadas principais (PCoA), realizada a partir da distância de Nei (1973), indica que as três primeiras coordenadas explicam 48,01\% da variabilidade genética entre os genótipos de Z. officinale (Figura 7C). A dispersão gráfica a partir das coordenas principais demonstra que os genótipos não formaram grupos exclusivos de acordo com a origem geográfica, o que também é demonstrado pelo método UPGMA e pela análise bayesiana (Figura 7).

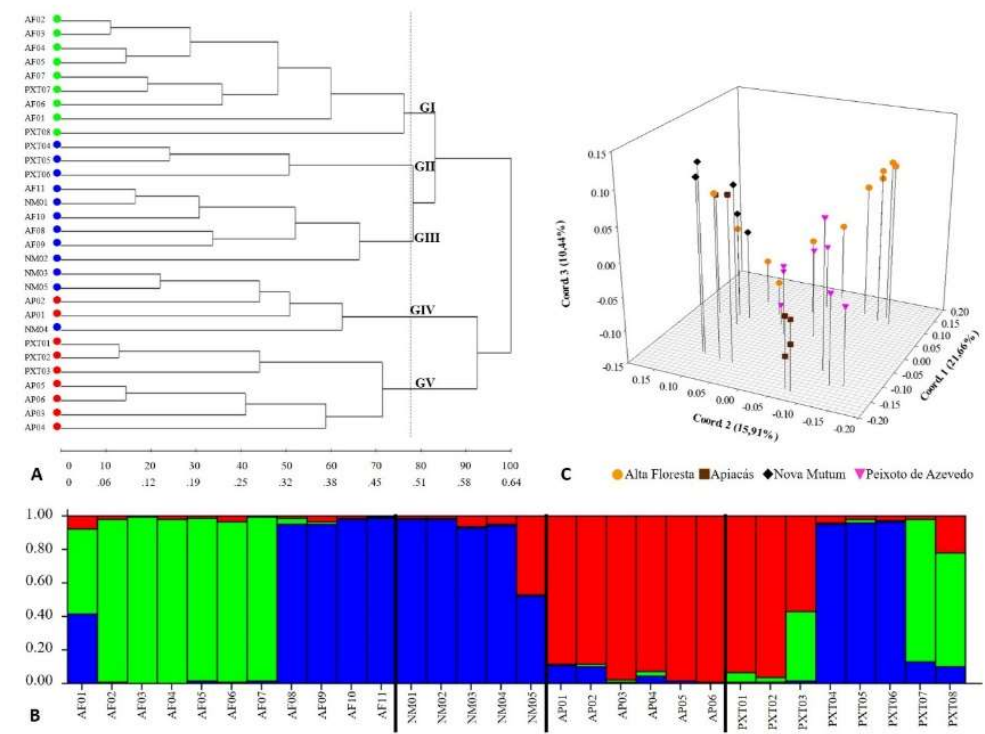

Figura 7: Agrupamentos dos 30 genótipos de Zingiber officinale. Alta Floresta (AF), Apiacás (AP), Nova Mutum (NM) e Peixoto de Azevedo (PXT); (A) Dendrograma de dissimilaridade genética obtido pelo método UPGMA, a partir da distância genética de Nei (1973). Ponto de Corte: 0,50 (78\%); Coeficiente de Correlação Cofenética (CCC): 0,78. (B)

Agrupamento segundo bases moleculares com oito primers SSR utilizando análise bayesiana, onde as cores representam os grupos genéticos. (C) Representação gráfica das três primeiras coordenadas principais (PCoA).

Os agrupamentos realizados não estão estritamente relacionados com a origem geográfica dos genótipos, uma vez que os grupos genéticos formados pela análise bayesiana são mistos, compostos por genótipos de municípios distintos, o que também é observado no agrupamento hierárquico pelo método UPGMA, onde, com exceção do GII, composto apenas por acessos oriundos de Peixoto de Azevedo, os grupos apresentam duas origens (GI: AF e PXT; GIII: AF e NM; GIV: AP e NM; GV: AP e PXT). A distribuição dos acessos oriundos de Peixoto de Azevedo (PXT) em quatro dos grupos formados pelo método UPGMA indica que o material proveniente deste município apresenta maior variabilidade genética quando comparado ao demais.

Resultados semelhantes foram observados por Das et al. (2017), ao avaliar a diversidade genética de 60 acessos de Z. officinale oriundos de cinco regiões da costa oriental da Índia utilizando marcadores ISSR e SSR, e por Kizhakkayil et al. (2010), utilizando ISSR e RAPD para caracterização molecular de 46 acessos de $Z$. officinale oriundos de diferentes países e mantidos no Instituto Indiano de Pesquisa de Especiarias (IISR). A ausência de relação direta entre região geográfica e grupos genéticos, demonstra que a troca de rizomas entre os agricultores possibilita o fluxo gênico, reduzindo a erosão genética e contribuindo para manutenção 
da diversidade, uma vez que a espécie se reproduz por propagação vegetativa.

A análise bayesiana organizou os genótipos em três grupos genéticos e apresenta similaridade com o UPGMA, sendo o grupo genético representado pela cor verde composto pelos mesmos genótipos do Gl do método UPGMA, contando com genótipos de AF e PXTO, enquanto o grupo vermelho é constituído por todos os genótipos do GV (oriundos de NM e AP) e dois do GIV (AP01 e AP02). O grupo azul, por sua vez, é constituído por todos os genótipos dos grupos II e III (provenientes de PXT, AF e NM) e por três do grupo IV (NM03, NM04, NM05). A figura 7B evidencia que os genótipos podem apresentar alelos oriundos de diferentes grupos genéticos, como é possível observar em NM05, onde aproximadamente 55\% do material genético é compatível com as informações do grupo representado pela cor azul e $45 \%$, com o do representado pela cor vermelha. Esse compartilhamento de alelos pode ser atribuído à base genética do material e sua história evolutiva, uma vez que o processo de reprodução característico da espécie não inclui recombinação e fusão de gametas parentais.

A ausência de relação entre a diversidade genética e a localização das populações coletadas foi evidenciada por três abordagens diferentes (UPGMA, análise bayesiana e PCoA) para análise da diversidade genética e corroborada pela análise de variância molecular (AMOVA), onde demonstrou-se que a variabilidade entre as populações contribui com apenas $25 \%$ da variação total, aproximadamente (Tabela 4).

Tabela 4: Análise de Variância Molecular (AMOVA) entre populações de Zingiber officinale com base em 8 primers SSR.

\begin{tabular}{lllllll}
\hline Fonte de Variação & GL & SQ & CV & VT & F & P \\
\hline Entre as populações & 3 & 19,722 & 0,375 & $25,13 \%$ & 0,2513 & $<0,001$ \\
Dentro das Populações & 56 & 62,628 & 1,118 & $74,87 \%$ & & \\
\hline Total & 59 & 82,350 & 1,493 & $100 \%$ & & \\
\hline
\end{tabular}

Grau de liberdade (GL), soma dos quadrados (SQ), componente de variância (CV), variância total (VT), divergência genética entre as populações ( $F_{S T}$ ) e probabilidades de ter um componente de variância maior que os valores observados ao acaso (P). As probabilidades foram calculadas a partir de 1023 permutações aleatórias.

O valor de diferenciação genética entre as populações, contudo, indica que as mesmas já apresentam certa estruturação, pois de acordo com Wright (1978), valores de $F_{S T}$ entre 0,15 e 0,25 indicam alta diferenciação genética, o que pode estar relacionada ao limitado fluxo gênico $(\mathrm{Nm}=0,845)$ entre as populações.

O fluxo gênico compreende o conjunto de mecanismos que promovem a movimentação dos genes entre populações, sofrendo influência do tipo de reprodução da espécie (autogamia ou alogamia) e outros processos como polinização, dispersão e ação antrópica. Considerando que a seleção natural tende a fixar alelos resultantes de mutações espontâneas, resultando em diferenciação e adaptação, o fluxo gênico age na disseminação desses alelos, impedindo a diferenciação à nível populacional (SLATKIN, 1987). No caso de Z. officinale, o fluxo gênico está limitado à troca de rizomas entre produtores e/ou distribuição dos mesmos para pessoas de seu círculo social, favorecendo, a longo prazo, o processo de fixação de alelos.

O processo de estruturação genética das populações também é corroborado pela pequena quantidade de alelos raros (Ar), encontrados apenas população de Alta Floresta ( $\mathrm{Ar}=2$ ), e de alelos exclusivos $(A e)$, encontrados em Alta Floresta $(A e=4)$, Nova Mutum $(A e=1)$ e Peixoto de Azevedo $(A e=2)$. De acordo com Cruz et al. (2011), alelos raros são encontrados em frequência $\leq 0,05$, enquanto que alelos exclusivos 
são aqueles encontrados em apenas uma das populações estudadas, sendo que esse alelo pode já ter sido fixado, por meio da seleção natural, ou ser um alelo novo.

A análise da diversidade genética a nível populacional pelo método UPGMA e PCoA representam esse processo de diferenciação entre as populações (Figura 8), sendo que para o método UPGMA todas as populações formam um único grupo, dentro do qual, Nova Mutum e Apiacás apresentam-se isolados (Figura $8 \mathrm{~A})$, assim como na PCoA (Figura 8B), onde as três coordenadas explicam 100\% da variabilidade genética entre as populações estudadas.
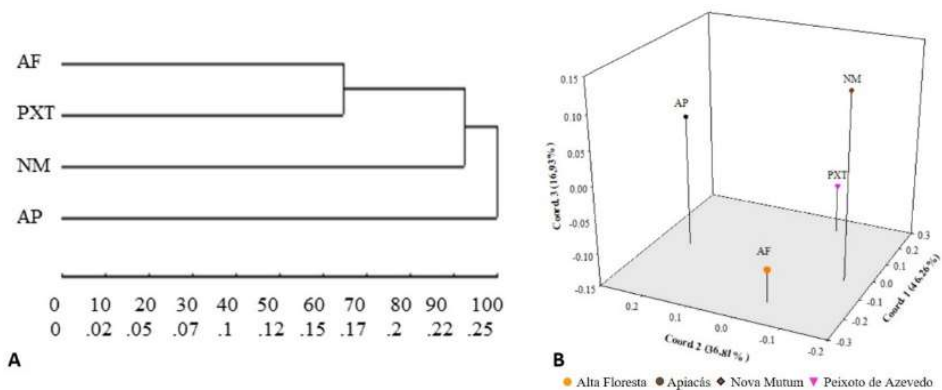

Figura 8: Agrupamentos das quatro populações de Zingiber officinale: Alta Floresta (AF), Apiacás (AP), Nova Mutum (NM) e Peixoto de Azevedo (PXT). (A) Dendrograma de dissimilaridade genética obtido pelo método UPGMA, a partir da distância genética de Nei (1973). Coeficiente de Correlação Cofenética (CCC): 0,66. (B) Dispersão gráfica a partir da análise das coordenadas principais obtida a partir de dados SSR.

Os resultados obtidos são consistentes com a história evolutiva do Z. officinale no Brasil, onde poucas variedades foram trazidas ainda no século XVI (PALHARIN et al., 2008), sendo estas mantidas e propagadas exclusivamente de forma vegetativa, de modo que a espécie apresenta uma base genética estreita que, por meio de mutação e seleção natural, tende a originar genótipos adaptados ao seu ambiente de cultivo, enquanto a troca de rizomas possibilita o fluxo gênico e a diversidade intra e interpopulacional.

\section{Análise conjunta: dados fenotípicos e moleculares}

A análise das matrizes de dissimilaridade dos dados fenotípicos (quantitativos e qualitativos) e dos dados moleculares demonstra padrões distintos, havendo correlação significativa pelo teste de Mantel apenas entre os dados quantitativos e moleculares, contudo, essa correlação é de apenas $5 \%$ e não foi significativa pelo teste t. A matriz de distância genética conjunta, por sua vez, apresentou correlação linear, positiva e significativa a nível de $1 \%$, tanto pelo teste t quanto pelo teste de Mantel (Tabela 5), com uma correlação entre 0,50 e 0,70, sendo classificada como moderada, de acordo com Miot et al. (2018), e indicando que, em média, 35\% das variações que nela ocorrem estão associadas aos agrupamentos das demais matrizes (quantitativa, qualitativa e molecular).

Tabela 5: Correlação entre as matrizes de distâncias dos dados fenotípicos (quantitativos e qualitativos). Moleculares (SSR) e análise conjunta (GOWER, 1971) para os genótipos de Zingiber officinale.

\begin{tabular}{lllll}
\hline Matrizes & Quantitativa & Qualitativa & Molecular & Conjunta \\
\hline Quantitativa & 1 & $0,051^{\mathrm{ns} ; \mathrm{ns}}$ & $0,053^{\mathrm{ns} ;++}$ & $0,623^{* * ;++}$ \\
Qualitativa & - & 1 & $-0,032^{\mathrm{ns} ; \mathrm{ns}}$ & $0,576^{* * ;++}$ \\
Molecular & - & - & 1 & $0,575^{* * ;++}$ \\
Conjunta & - & - & - & 1 \\
\hline
\end{tabular}

ns, ${ }^{* *}$ : Não significativo, significativo a $1 \%$ de probabilidade pelo teste $t .{ }^{\text {ns }},{ }^{++}$: Não significativo, significativo a $1 \%$ de probabilidade pelo teste de Mantel baseado em 1000 simulações. 
A ausência e/ou baixa correlação para as matrizes de dissimilaridade dos dados fenotípicos entre si e com os moleculares indica que os resultados obtidos por um conjunto de dados não podem ser utilizados para inferir os resultados de outro conjunto, sendo, portanto, indicada a análise conjunta que poderá possibilitar uma melhor compreensão da variabilidade entre os genótipos estudados (MARTINS et al., 2011; STRECK et al., 2017). A baixa correlação pode ser explicada pela natureza dos dados, pois enquanto os primers SSR incluem regiões codificantes e não codificantes do genoma (BORÉM et al., 2016), os marcadores fenotípicos representam a expressão de regiões codificantes.

A análise conjunta por meio do método UPGMA, baseado na distância de Gower, formou quatro grupos genéticos (Figura 9), sendo que $87 \%$ dos genótipos estão alocados no Grupo I, incluindo todos os genótipos oriundos de Alta Floresta e Nova Mutum e ainda 66\% dos provenientes de Apiacás e 75\% de Peixoto de Azevedo. O Gll é composto apenas por genótipos procedentes de Apiacás (AP04 e AP05), sendo estes os que apresentaram rizoma de maior espessura, estando também entre os três genótipos de maior produtividade por indivíduo, porém diferenciando-se, entre si, quanto ao hábito de crescimento, padrão de união da bainha, tamanho da lígula, ápice e comprimento da folha. Os grupos GIII e GIV são compostos por representantes únicos, sendo que estes também foram alocados em grupos distintos quando realizadas, separadamente, as análises quantitativas, qualitativas e moleculares. O GIII é constituído por PXT08, que se destaca pelo número de perfilhos por planta e por apresentar folhas muito estreitas. O GIV, por sua vez, é composto apenas pelo genótipo PXT06, sendo este o que apresentou menores valores para altura da planta, comprimento da folha e produtividade do rizoma, de modo que não seja indicado para cultivo com interesse comercial. O genótipo PXT06 apresentou-se como o mais distante geneticamente tanto pela análise conjunta quanto pelas análises isoladas dos dados moleculares e os fenotípicos quantitativos.

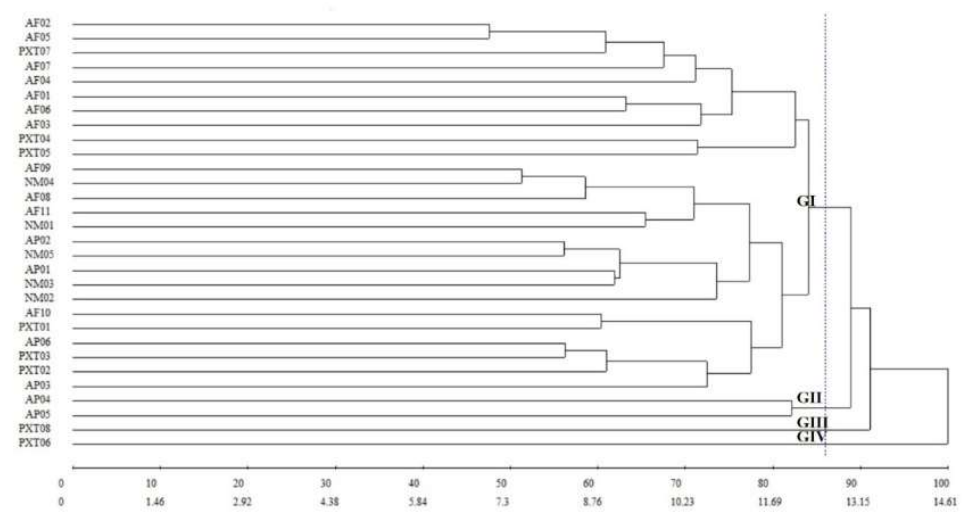

Figura 9: Agrupamento resultante da análise conjunta dos dados fenotípicos qualitativos e quantitativos e dos dados moleculares (SSR) para 30 genótipos de Zingiber officinale. Alta Floresta (AF), Apiacás (AP), Nova Mutum (NM) e Peixoto de Azevedo (PXT); Dendrograma de dissimilaridade genética obtido pelo método UPGMA, a partir da distância de Gower (1971). Ponto de Corte: 12,57 (86\%). Coeficiente de Correlação Cofenética (CCC): 0,66.

Os coeficientes de correlação cofenética (CCC) foram significativos tanto para as matrizes fenotípicas (qualitativa e quantitativa) e molecular, avaliadas separadamente, quanto para a análise conjunta, demonstrando o grau consistência dos agrupamentos, uma vez que valores $\geq 0,70$ e/ou significativos indicam que existe um bom ajuste entre a matriz de dissimilaridade original e o dendrograma (ROHLF, 1970).

Embora o CCC para a análise conjunta tenha sido menor que 0,7, o mesmo foi considerado 
significativo, indicando um bom ajuste entre os agrupamentos obtidos e a matriz de distância original. O agrupamento a partir na análise conjunta apresentou 1,18\% de distorção e 10,84\% de estresse, o que reafirma a consistência do agrupamento, uma vez que estresses entre 10 e $20 \%$ são considerados bons em indicar a eficiência do ajuste do dendrograma, sendo que quanto mais próximo de 10 , melhor o ajuste (KRUSKAL, 1964). Os resultados deste estudo indicam a importância da utilização dos descritores fenotípicos, relacionados às características de interesse comercial, e dos marcadores moleculares para caracterização e identificação da diversidade genética entre genótipos de $Z$. officinale, e sugerem ainda que a associação entre esses descritores, demonstrada pela análise conjunta, possibilita uma avaliação mais abrangente do material estudado.

\section{CONCLUSÕES}

Os genótipos de Zingiber officinale avaliados neste estudo apresentam diversidade genética, tanto a nível molecular quanto fenotípico e também pela análise conjunta desses dados. Sendo assim, a melhor forma de caracterização do material compreende a utilização, complementar e conjunta, de marcadores moleculares e descritores fenotípicos quantitativos e qualitativos. Os resultados permitem inferir que, embora a pressão seletiva indique um processo de diferenciação entre as populações Zingiber officinale estudadas, o fluxo gênico, promovido pelos produtores, tem contribuído para manutenção da diversidade genética tanto entre genótipos quanto entre populações, enfatizando a importância dos cultivares locais, oriundos de conservação on farm, para programas de melhoramento genético da espécie, bem como a inserção desses cultivares em bancos de conservação ex situ.

\section{REFERÊNCIAS}

AKSHITHA, H. J.; UMESHA, K.; PRASATH, D.. Morphological characterization of ginger (Zingiber officinale) using DUS descriptors. Indian Journal of Agricultural Sciences, v.89, n.10, p.1744-1747, 2019.

ALVARES, C. A.; STAPE, J. L.; SENTELHAS, P. C.; GONÇALVES, J. L. M.; SPAROVEK, G.. Koppen's climate classification map for Brazil. Meteorologische Zeitschrift, v.22, n.6, p.711-728, 2013. DOI: http://doi.org/10.1127/0941-2948/2013/0507

BABU, M. S.; KUMAR, B. P.; SWAMI, D. V.; KRISHNA, K. U.; EMMANUEL, N.. Performance of ginger (Zingiber officinale Rosc) varieties under shade net condition of Costal Andhra Pradesh. International Journal of Current Microbiology and Applied Sciences, v.6, n.7, p.494-498, 2017. DOI: http://doi.org/10.20546/ijcmas.2017.607.059

BALOGUN, F. O.; OLUWA, E. T.; ASHAFA, A. O. T.. Pharmacological potentials of ginger. In: WANG, H.. Ginger cultivation and its antimicrobial and pharmacological potentials. London: IntechOpen, 2020. p.1-20. DOI: http://doi.org/10.5772/intechopen.88848

BASAK, D.; CHAKRABORTY, A.; SARKAR, M. K.; DEBNATH, K. A.; KHALKO, S.. Characterization and genetic potential of ginger genotypes evaluated in Terai Region of west Bengal, India. International Journal of Current Microbiology and
Applied Sciences, v.8, n.4, p.1147-1158, 2019. DOI: http://doi.org/10.20546/ijcmas.2019.804.132

BERNARDO, R.. Breeding for quantitative traits in plants. 2 ed. Woodbury: University of Minnesota, 2010.

BLANCO, E. Z.. Diversidade genética e química em germoplasma de gengibre (Zingiber officinale). Tese (Doutorado em Genética e Melhoramento de Plantas) Universidade de São Paulo, Piracicaba, 2015. DOI: http://doi.org/10.11606/T.11.2015.tde-05052015-104359

BLANCO, E. Z.; BAJAY, M. M.; SIQUEIRA, M. V. B. M.; ZUCHI, M. I.; PINHEIRO, J. B.. Genetic diversity and structure of Brazilian ginger germplasm (Zingiber officinale) revealed by AFLP markers. Genetica, v.144, n.6, p.627-638, 2016. DOI: http://doi.org/10.1007/s10709-016-9930-1

BLANCO, E. Z.; PINHEIRO, J. B.. Agronomic evaluation and clonal selection of ginger genotypes (Zingiber officinale Roscoe) in Brazil. Agronomía Colombiana, v.35, n.3, p.275284, 2017. DOI:

http://doi.org/10.15446/agron.colomb.v35n3.62454

BORÉM, A.; CAIXETA, E. T.. Marcadores moleculares. Viçosa: UFV, 2016. 
BOTSTEIN, D.; WHITE, R. L.; SKOLNICK, M.; DAVIS, R. W.. Construction of a genetic linkage map in man using restriction fragment length polymorphisms. American Journal of Human Genetics, v.32, n.3, p.314-331, 1980.

CARDOSO, E. S.; ROSSI, A. A. B.; PEDRI, E. C. M.; BISPO, R. B.; OLIVEIRA, U. A.; SILVA, V. P.. Conhecimento e uso do gengibre por familiares de alunos de duas unidades escolares de Alta Floresta/MT. Gaia Scientia, v.12, n.3, p.145-154, 2018. DOI: http://doi.org/10.22478/ufpb.1981$1268.2018 \mathrm{v} 12 \mathrm{n} 3.38936$

CARMO, C. A. S.; BALBINO, J. M. S.. Gengibre. Vitória: Incaper, 2015.

COLE-RODGERS, P.; SMITH, D. W.; BOSLAND, P. W.. A novel statistical approach to analyze genetic resource evaluations using Capsicum as an example. Crop Science, v.37, n.3, p.1000-1002, 1997. DOI: http://doi.org/10.2135/cropsci1997.0011183x00370003005 Ox

CRUZ, C. D.. Programa GENES: análise multivariada e simulação. Viçosa: UFV, 2006.

CRUZ, C. D.. Genes Software: extended and integrated with the R, Matlab and Selegen. Acta Scientiarum. Agronomy, v.38, n.4, p.547-552, 2016. DOI: https://doi.org/10.4025/actasciagron.v38i3.32629

CRUZ, C. D.; FERREIRA, M. F.; PESSONI, L. A.. Biometria aplicada ao estudo da diversidade genética. Visconde do Rio Branco: Suprema, 2011.

DAS, A.; GAUR, M.; BARIK, D. P.; SUBUDHI, E.. Genetic diversity analysis of 60 ginger germplasm core accessions using ISSR and SSR markers. Plant Biosystems - An International Journal Dealing with all Aspects of Plant Biology, v.151, n.5, p.822-832, 2017. DOI: http://doi.org/10.1080/11263504.2016.1211197

DAS, A.; SAHOO, R. S.; BARIK, D. P.; SUBUDHI, E.. Identification of duplicates in ginger germplasm collection from Odisha using morphological and molecular characterization. Proceedings of the National Academy of Sciences, India Section B: Biological Sciences, v.90, p.10571066, 2020. DOI: http://doi.org/10.1007/s40011-020-01178$\mathrm{y}$

DOYLE, J. J.; DOYLE, J. L.. A rapid DNA isolation procedure for small quantities of fresh leaf tissue. Phytochemical Bulletin, v.19, n.1, p.11-15, 1987.

EVANO, G.; REGNAUT, S.; GOUDET, J.. Detecting the number of clusters of individuals using the software structure: a simulation study. Molecular Ecology, v.14, n.8, p.2611-2620, 2005. DOI: http://doi.org/10.1111/i.1365-

294X.2005.02553.X

EXCOFFIER, L.; LAVAL, G.; SCHNEIDER, S.. Arlequin (versão 3.0): An Integrated Software Package for Population Genetics Data Analysis. Evolutionary Bioinformatics Online, v.1, p.47-50, 2005. DOI: http://doi.org/10.1177/117693430500100003

FERREIRA, E. L.; CARDOSO, E. S.; RODRIGUES, A. S.; ROSSI, A. A. B.. Conhecimento e utilização do gengibre no norte de
Mato Grosso. Revista Vivências, v.16, n.31, p.157-169, 2020. DOI: http://doi.org/10.31512/vivencias.v16i31.230

GOWER, J. C.. A general coefficient of similarity and some of its properties. Biometrics, v.27, n.4, p.857-871, 1971. DOI: http://doi.org/10.2307/2528823

HARTL, D. L.; CLARK, A. G.. Princípios de Genética de Populações. 4 ed. Porto Alegre: Artmed, 2010.

JATOI, S. A.; ZEHRA, A.; WATANABE, K. N.. Morphoagronomic caracterization and genetic variability assessment in mango-ginger (Curcuma amada; Zingiberaceae). Gomal University Journal of Research, v.31, n.2, 2015.

KIZHAKKAYIL, J.; SASIKUMAR, B.. Genetic diversity analysis of ginger (Zingiber officinale Rosc.) germplasm based on RAPD and ISSR markers. Scientia Horticulturae, v.125, n.1, p.7376, 2010. DOI: http://doi.org/10.1016/j.scienta.2010.02.024

KRUSKAL, J. B.. Multidimensional scaling by optimizing goodness of fit to a nonmetric hypothesis. Psychometrika, v.29, n.1, p.1-27, 1964.

LEE, S.-Y.; FAI, W. K.; ZAKARIA, M.; IBRAHIM, H.; OTHMAN, R. Y.; GWAG, J.-G.; RAO, V. R.; PARK, Y.-J.. Characterization of polymorphic microsatellite markers, isolated from ginger (Zingiber officinale Rosc.). Molecular Ecology Notes, v.7, n.6, p.1009-1011, 2007. DOI: http://doi.org/10.1111/i.14718286.2007.01757.x

LIU, K.; MUSE, S. V.. Power Marker: Integrated analysis environment for genetic marker data. Bioinformatics, v.21, n.9, p.2128-2129, 2005. DOI:

http://doi.org/10.1093/bioinformatics/bti282

MANTEL, N.. The detection of disease clustering and a generalized regression approach. Cancer Research, v.27, n.2, p.209-220, 1967.

MARTINS, F. A.; CARNEIRO, P. C. S.; SILVA, D. J. H.; CRUZ, C. D.; CARNEIRO, J. E. S.. Integração de dados em estudos de tomateiro. Pesquisa Agropecuária Brasileira, v.46, n.11, p.1496-1502, 2011. DOI: http://doi.org/10.1590/S0100204X2011001100011

MIOT, H. A.. Análise de correlação em estudos clínicos e experimentais. Jornal Vascular Brasileiro, v.17, n.4, p.275279, 2018. DOI: http://doi.org/10.1590/1677-5449.174118

MOJENA, R.. Hierarchical grouping methods and stopping rules: an evaluation. The Computer Journal, v.20, n.4, p.359363, 1977. DOI: https://doi.org/10.1093/comjnl/20.4.359

NANDKANGRE, H.; QUEDRAOGO, M.; SAWADOGO, M.; BADO, S.; SAWADOGO, N.; OUOBA, A.; KONATE, M. N.. Morphometric and agronomic characterization of 56 ginger landrace in Burkina Faso. Journal of Applied Biosciences, v.100, p.9545-9566, 2016. DOI: http://doi.org/10.4314/jab.v100i1.6

NATIONMASTER. Statistics Database. Top Countries in Ginger Production: 1961 to 2019. NATIONMASTER, 2020a.

NATIONMASTER. Statistics Database. Top Countries in Export of Ginger: 1988 to 2019. NATIONMASTER, 2020b. 
NEI, M.. Analysis of gene diversity in subdivided populations. Proceedings of the National Academy of Sciences of the United States of America, v.70, n.12, p.3321-3323, 1973. DOI: http://doi.org/10.1073/pnas.70.12.3321

PALHARIN, L. H. C.; FIGUEIREDO NETO, E.; LOPES, M. P. C.; BOSQUÊ, G. G.. Estudo sobre o gengibre na medicina popular. Revista Científica Eletrônica de Agronomia, v.7, n.14. p.1-4, 2008.

PANDOTRA, P.; GUPTA, A. P.; HUSAUN, M. K.; GHANDIRAN; GUPTA, S.. Evaluation of genetic diversity and chemical profile of ginger cultivars in north-western Himalayas. Biochemical Systematics and Ecology, v.48, p.281-287, 2013. DOI: http://doi.org/10.1016/j.bse.2013.01.004

PEAKALL, R.; SMOUSE, P. E.. GenAIEx 6.5: genetic analysis in Excel. Population genetic software for teaching and research - an update. Bioinformatics, v.28, n.19, p.2537-2539, 2012. DOI: http://doi.org/10.1093/bioinformatics/bts460

PPV \& FRA. Protection of Plant Varieties \& Farmers' Rights Authority, Government of India. Crop Guidelines: ginger. PPV \& FRA, 2007.

PRITCHARD, J. K.; STEPHENS, M.; DONNELLY, P.. Inference of population structure using multilocus genotype data. Genetics, v.155, n.2, p.945-959, 2000.

PRITCHARD, J. K.; WEN, X.; FALUSH, D.. Documentation for structure software: Version 2.3. 2009.

RAVINDRAN, P. N.; BABU, K. N.. Ginger: The genus Zingiber. Washington: CRC Press, 2016.

ROHLF, F. J.. Adaptative hierarchical clustering schemes. Systematic Zoology, v.19, n.1, p.58-82, 1970.

SANTONIERI, L.; BUSTAMANTE, P. G.. Conservação ex situ e on farm de recursos genéticos: desafios para promover sinergias e complementaridades. Boletim do Museu Paraense Emílio Goeldi. Ciências Humanas, v.11, n.3, p.677690, 2016. DOI:

http://doi.org/10.1590/1981.81222016000300008

SHIVAKUMAR, N.. Biotechnology and crop improvement of ginger (Zingiber officinale Rosc.). In: WANG, H.. Ginger cultivation and its antimicrobial and pharmacological potentials, London: IntechOpen, 2020. p.1-14. DOI: http://doi.org/10.5772/intechopen.88574

SIDRA. Sistema IBGE de Recuperação Automática. Acervo: censo agropecuário. SIDRA, 2017.

SILVA, C. J.; TEODORO, C.; IRIGARAY, J. H.; FARIA, A. M. M.; RIBEIRO, A. R.. Formação Socioambiental do Estado de Mato Grosso. In: SIMONIAN, L. T. L.; BAPTISTA, E. R.. Formação socioambiental da Amazônia. Belém: NAEA, 2015. v.1, p.319-380.
SINGH, D.. The relative importance of characters affecting genetic divergence. Indian Journal of Genetics and Plant Breeding, v.41, n.2, p.237-245, 1981

SLATKIN, M.. Gene flow and the geographic structure of natural populations. Science, v.236, n.4803, p.787-792, 1987. DOI: http://doi.org/10.1126/science.3576198

SOKAL, R. R.; ROHLF, F. J.. The comparison of dendograms by objective methods. Taxon, v.11, n.2, p.33-40, 1962. DOI: https://doi.org/10.2307/1217208

SRINIVASAN, K.. Ginger rhizomes (Zingiber officinale): A spice with multiple health beneficial potentials. Pharma Nutrition, v.5, n.1, p.18-28, 2017. DOI:

http://doi.org/10.1016/j.phanu.2017.01.001

STRECK, E. A.; AGUIAR, G. A.; MAGALHÃES JÚNIOR, A. M.; FACCHINELLO, H. K.; OLIVEIRA, A. C.. Variabilidade fenotípica de genótipos de arroz irrigado via análise multivariada. Revista Ciência Agronômica, v.48, n.1, p.101-109, 2017. DOI: http://doi.org/10.5935/1806-6690.20170011

SUBUDHI, E.; DAS, A.; JOSHI, R. K.; MOHANTY, S.; NAYAK, S.. Genetic diversity analysis and redundant identification in 48 core collections of Zingiber officinale Rosc. (Zingiberaceae). Brazilian Journal of Botany, v.39, n.6, p.869-883, 2016. DOI: http://doi.org/10.1007/s40415-016-0278-7

SYSTAT SOFTWARE. SigmaPlot for Windows: Version 12.0. San Jose: Systat Software Inc., 2011.

VIEIRA, E. A.; FIALHO, J. F.; FALEIRO, F. G.; BELLON, G.; FONSECA; K. G.; CARVALHO, L. J. C. B.; SILVA, M. S.; PAULAMORAES, S. V.; SANTOS FILHO, M. O. S.; SILVA, K. N.. Divergência genética entre acessos açucarados e não açucarados de mandioca. Pesquisa Agropecuária Brasileira, v.43, n.12, p.1707-1715, 2008. DOI:

http://doi.org/10.1590/S0100-204X2008001200010

WAKCHAURE, R.; GANGULY, S.. Phytochemistry and pharmacological properties of ginger (Zingiber officinale). In: MAHDI, A. A. et al. Molecular Biology and Pharmacognosy and Beneficial Plants. Delhi: Lenin Media PVT. LTD., 2018. p.97-103.

WICAKSANA, N.; GILANI, S. A.; AHMAD, D.; KIKUCHI, A.; WATANABE, K. N.. Morphological and molecular characterization of underutilized medicinal wild ginger (Zingiber barbatum Wall.) from Myanmar. Plant genetic resources, v.9, n.4, p.531-542, 2011. DOI: http://doi.org/10.1017/S1479262111000840

WRIGHT, S.. Evolution and Genetics of Populations. Chicago: University of Chicago, 1978.

YEH, F. C.; YANG, R. C.; BOYLE, T. B. J.; YE, Z.; XIYAN, J. M.; YANG, R.; BOYLE, T. J.. POPGENE version 1.32: Microsoft Window-based freeware for population genetic analysis. Edmonton: University of Alberta, 2000.

A CBPC - Companhia Brasileira de Produção Científica (CNPJ: 11.221.422/0001-03) detém os direitos materiais desta publicação. Os direitos referem-se à publicação do trabalho em qualquer parte do mundo, incluindo os direitos às renovações, expansões e disseminações da contribuição, bem como outros direitos subsidiários. Todos os trabalhos publicados eletronicamente poderão posteriormente ser publicados em coletâneas impressas sob coordenação da Sustenere Publishing, da Companhia Brasileira de Produção Científica e seus parceiros autorizados. Os (as) autores (as) preservam os direitos autorais, mas não têm permissão para a publicação da contribuição em outro meio, impresso ou digital, em português ou em tradução. 